Editorial

\title{
Molecular System Bioenergetics-New Aspects of Metabolic Research
}

\author{
Valdur Saks ${ }^{1,2, *}$
}

1 INSERM U884, Laboratoire de Bioénergétique Fondamentale et Appliquée, Université Joseph Fourier 2280 Rue de la Piscine, BP 53, Grenoble Cedex 9, France

2 Laboratory of Bioenergetics, National Institute of Chemical Physics and Biophysics, Akadeemia tee 23, 12618 Tallinn, Estonia

* Author to whom correspondence should be addressed; E-Mail: Valdur.Saks@ujf-grenoble.fr; Tel. +33-476635627; Fax: +33-476514218

Received: 28 July 2009 / Accepted: 18 August 2009 / Published: 19 August 2009

Keywords: molecular system bioenergetics; metabolism; systems biology; respiration; mitochondria

This Special Issue is a significant step in developing a new direction of metabolic researchMolecular System Bioenergetics, which itself is a part of Systems Biology. As a new paradigm of biological sciences, Systems Biology aims at understanding of biological functions by studies and description of new, system level properties, resulting from interactions between components of biological systems at any level of organization, from molecular to population. Metabolism is the way of life of cells by exchanging mass and energy with the surrounding medium, and understanding its mechanisms requires knowledge of the complex interactions between cellular systems and components. While studies of metabolism have a long history, new concepts of Systems Biology provide useful tools for metabolic research. According to Schrödinger, living cells need to be open systems with energy and mass exchange with the surrounding medium, with the aim of maintaining their high structural and functional organization and thus their internal entropy low, achieving this by means of increasing the entropy of the medium by catabolic reactions [1]. Thus, Schrödinger wrote: "The essential thing in metabolism is that the organism succeeds in freeing itself from all entropy it cannot help producing while alive" [1]. Thus, free energy conversion in the cells is an important, central part of metabolism, and understanding the complex mechanisms of its regulation is the aim of 
Molecular System Bioenergetics [2]. In this Special Issue, several important problems in this field were analyzed.

Two articles have focused on the historical roots and philosophical basis of Systems Biology $[3,4]$. These roots can be traced back as far as to the works of Harvey on circulation [3], to the discovery of homeostasis by Bernard $[3,4]$, followed by creation of cybernetic theory of feedback regulation and information networks by Wiener, and the important and famous analysis of thermodynamic aspects of metabolism by Schrödinger [1] already mentioned above. In general, these developments and exponential growth of Systems Biology in recent years perfectly fit with the Hegel's philosophical predictions of dialectic developments of historical processes when applied to biology [4].

The next two articles deal with experimental and theoretical methods of studies of interactions between cellular components [5,6]. One of them [5] describes two-hybrid methods of studies of protein-protein interactions [5], and the second deals with theoretical basis and experimental analysis of metabolic fluxes by isotopomer analysis [6]. Then, the following chapter deals with experimental analysis of phosphotransfer networks [7]. These analyses may provide a good basis for further mathematical modelling of organized metabolic systems.

After these chapters of general interest, the focus of interest of authors is fixed on mitochondriaon the energetic factories of the cells. One of the most important directions of the bioenergetics of the cells in vivo are studies of mitochondrial organization and dynamics by confocal microscopy and image analysis, as described in [8], and in [9] new evidence is given for the existence of a novel mitochondrial potassium channel. This is followed by a mathematical analysis of mitochondrial functional behavior in vivo by applying the methods of Metabolic Control Analysis in [10].

The last group of articles, [11-14], deals with an important application of Molecular System Bioenergetics - mitochondrial pathologies. These papers describe the phenomenon of energetic depression [11], the application of the system biology approach in studies of apoptosis [12], in cancer research [13] and finally, in obesity and ageing [14].

Taken together, all articles published describe well the most interesting current directions in cellular energetics and metabolism studies. It is a pleasure of the Guest Editor to thank all authors for their important contributions into this Special Issue and development of the new direction of Molecular System Bioenergetics.

\section{References and Notes}

1. Schrödinger, E. What Is Life? Cambridge University Press: Cambridge, UK, 1944.

2. Saks, V. Molecular System Bioenergetics; Saks, V., Ed.; Wiley-VCH: Weinheim, Germany, 2007; pp. 1-604.

3. Auffray, C.; Noble, D. Origins of Systems Biology in William Harvey's Masterpiece on the Movement of the Heart and the Blood in Animals. Int. J. Mol. Sci. 2009, 10, 1658-1669.

4. Saks, V.; Monge, C.; Guzun, R. Philosophical Basis and Some Historical Aspects of Systems Biology: From Hegel to Noble-Applications for Bioenergetic Research. Int. J. Mol. Sci. 2009, 10, 1161-1192.

5. Brückner, A.; Polge, C.; Lentze, N.; Auerbach, D.; Schlattner, U. Yeast Two-Hybrid, a Powerful Tool for Systems Biology. Int. J. Mol. Sci. 2009, 10, 2763-2788. 
6. Schryer, D.W.; Peterson, P.; Paalme, T.; Vendelin, M. Bidirectionality and Compartmentation of Metabolic Fluxes Are Revealed in the Dynamics of Isotopomer Networks. Int. J. Mol. Sci. 2009, 10, 1697-1718.

7. Dzeja, P.; Terzic, A. Adenylate Kinase and AMP Signaling Networks: Metabolic Monitoring, Signal Communication and Body Energy Sensing. Int. J. Mol. Sci. 2009, 10, 1729-1772.

8. Kuznetsov, A.V.; Margreiter, R. Heterogeneity of Mitochondria and Mitochondrial Function within Cells as Another Level of Mitochondrial Complexity. Int. J. Mol. Sci. 2009, 10, 19111929.

9. Skalska, J.; Bednarczyk, P.; Piwońska, M.; Kulawiak, B.; Wilczynski, G.; Dołowy, K.; Kunz, W.S.; Kudin, A.P.; Szewczyk, A. Calcium Ions Regulate K+ Uptake into Brain Mitochondria: The Evidence for a Novel Potassium Channel. Int. J. Mol. Sci. 2009, 10, 1104-1120.

10. Cortassa, S.; O’Rourke, B.; Winslow, R.L.; Aon, M.A. Control and Regulation of Integrated Mitochondrial Function in Metabolic and Transport Networks. Int. J. Mol. Sci. 2009, 10, 15001513.

11. Seppet, E.; Gruno, M.; Peetsalu, A.; Gizatullina, Z.; Nguyen, H.P.; Vielhaber, S.; Wussling, M.H.; Trumbeckaite, S.; Arandarcikaite, O.; Jerzembeck, D.; Sonnabend, M.; Jegorov, K.; Zierz, S.; Striggow, F.; Gellerich, F.N. Mitochondria and Energetic Depression in Cell Pathophysiology. Int. J. Mol. Sci. 2009, 10, 2252-2303.

12. Jekabsons, M.B. A Systems Biology Approach to Investigating Apoptotic Stimuli as Effectors of Cell Metabolism: Practical Application of Top-Down Control Analysis to Attached Neurons. Int. J. Mol. Sci. 2009, 10, 702-722.

13. Lee, H.-C.; Wei, Y.-H. Mitochondrial DNA Instability and Metabolic Shift in Human Cancers. Int. J. Mol. Sci. 2009, 10, 674-701.

14. Chanséaume, E.; Morio, B. Potential Mechanisms of Muscle Mitochondrial Dysfunction in Aging and Obesity and Cellular Consequences. Int. J. Mol. Sci. 2009, 10, 306-324.

(C) 2009 by the authors; licensee Molecular Diversity Preservation International, Basel, Switzerland. This article is an open-access article distributed under the terms and conditions of the Creative Commons Attribution license (http://creativecommons.org/licenses/by/3.0/). 